\title{
Biofilm biofertilizer can reinstate network interactions for improved rice production
}

M. Premarathna, G. Seneviratne*, K.G. Ketipearachchi, A. Pathirana, R.K.C. Karunaratne, W.K. Balasooriya and K. Fonseka

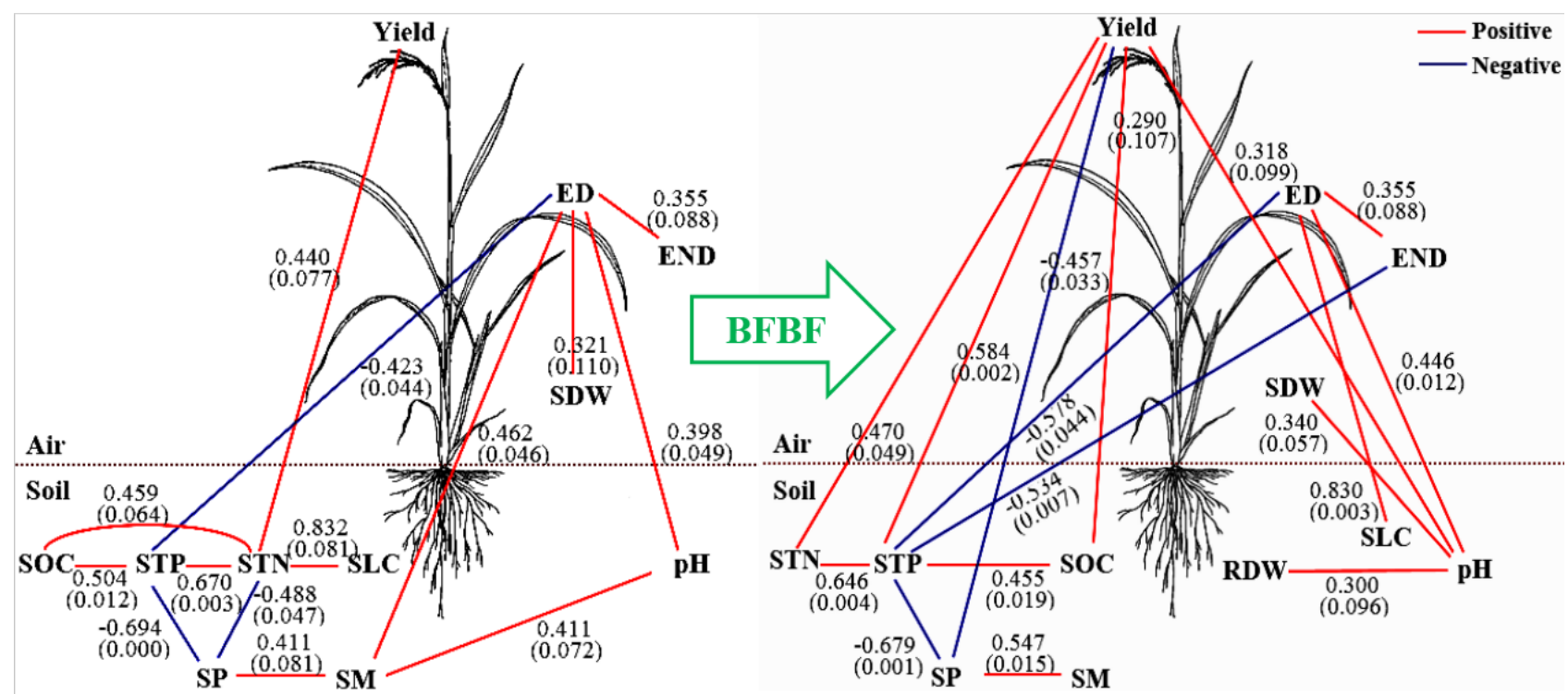

\section{Highlights}

- BFBFs contain sub network components of the agro-ecosystems.

- The sub network components help repair degraded bulk network of the agro-ecosystems.

- Thus, BFBF application helps reduce chemical fertilizers use, while increasing crop yield.

- As such, the BFBFs contribute to design eco-friendly agro-ecosystems with sustainability. 


\title{
RESEARCH ARTICLE
}

\section{Biofilm biofertilizer can reinstate network interactions for improved rice production}

\author{
M. Premarathna ${ }^{1}$, G. Seneviratne ${ }^{1, *}$, K.G. Ketipearachchi ${ }^{2}$, A. Pathirana ${ }^{1}$, R.K.C. Karunaratne ${ }^{1}$, \\ W.K. Balasooriya ${ }^{3}$ and K. Fonseka ${ }^{2}$
}

\begin{abstract}
${ }^{1}$ Microbial Biotechnology Unit, National Institute of Fundamental Studies, Hantana Road, Kandy, Sri Lanka. ${ }^{2}$ Department of Crop Science, Faculty of Agriculture, University of Ruhuna, Mapalana, Kamburupitiya, Sri Lanka. ${ }^{3}$ Department of Biotechnology, Faculty of Agriculture and Plantation Management, Wayamba University of Sri Lanka. Makandura, Gonawila (NWP).
\end{abstract}

Received: 02/02/2021; Accepted:15/08/2021

\begin{abstract}
Biofilms are complex communities of multiple microbial species which are attached to surfaces or physical interfaces in nature. Such biofilms can also be developed in vitro using beneficial microbes, and can be used as Biofilm biofertilizers (BFBFs). Once applied, the BFBFs can supply sub network components to the bulk network of soil-plant-microbe parameters in agro-ecosystems degraded due to excessive use of chemical inputs. Thus, the degraded ecosystems can get their bulk network repaired through the sub network substitutions for improved interactions. Here, we analyzed selected soil, plant and microbial parameters with the application of farmers' chemical fertilizers (CF) alone practice [425 kg CF/ha(Urea 284, TSP 76 and MOP $66 \mathrm{~kg} / \mathrm{ha})]$ and BFBF practice [2.5 L of BFBF with $225 \mathrm{~kg} \mathrm{CF} / \mathrm{ha}$ (Urea 150, TSP 40 and MOP $35 \mathrm{~kg} / \mathrm{ha}$ )] in 37 different locations in Sri Lanka using rice (Oryza sativa L.) as the test crop. Further, the data were analyzed to reveal the effect of BFBF in re-establishing networks in the agro-ecosystems. The BFBF application helped in cutting down farmers' CF use up to ca. $50 \%$, while increasing grain yield up to $c a$. $25 \%$. This was attributed to the positive effects of the BFBF towards strengthening the network interactions of the soil, plant and microbes. In this manner, BFBF practice clearly showed its potential as an ecofriendly and economically viable method to replace the farmers' current adverse practice of $\mathrm{CF}$ alone application. However, further studies should be conducted to collect data of a large number of variables, and they should be analyzed using more advanced methods to understand, particularly biotic and abiotic stresses for addressing them more effectively. This will eventually lead to design eco-friendly agro-ecosystems for sustainable agriculture.
\end{abstract}

Keywords: Agro-ecosystem; biofilm biofertilizers; microbial communities; networks.

\section{INTRODUCTION}

Everything in nature is interconnected or networked, directly or indirectly, and they are continuously interacting, positively (synergistically) or negatively (antagonistically). Balance of those interactions is important for stability and hence sustenance of any system (Aussenac et al., 2019). In ecosystems, functional stability is strongly influenced by diverse microbial communities in the soil (Wittebolle et al., 2009). There are signal-mediated interactions between plants and microbes. Plant-microbe interactions control ecosystems, and they potentially represent a mechanistic link between plant diversity and ecosystem function (Zak et al., 2003; Seneviratne, 2015).

In agro-ecosystems, modern agriculture is one of the greatest extinction threats to biodiversity (Jackson et al., 2005). Tillage (Njaimwe et al., 2018) and chemical inputs (Tilman et al., 2002) disrupt physical, chemical and biological soil quality parameters causing network degradation and ultimately collapsing of sustainability. Chemical inputs, particularly $\mathrm{N}$ fertilizers and pesticides reduce microbial diversity (Van der Heijden et al., 2006; Hadgu et al., 2009; Pang et al., 2017; Kumar et al., 2018), mainly $\mathrm{N}_{2}$ fixers. Here, microbial cells forming seeds enter in to a dormant phase in order to bypass the stress conditions like the applied chemicals (Seneviratne and Kulasooriya, 2013). Moreover, the agricultural chemicals deplete natural bio chemicals like soil enzymes (Chen et al., 2018), thus relapsing protein, metabolic and signaling networks (Fox et al., 2007). Thus, an urgent attention is needed to look for methods to reinstate the collapsed networks for re-establishing agro-ecosystem sustainability. Microbial interventions have been shown to be capable enough to address this issue to some extent (Alori and Babalola, 2018).

In the nature, microbes live in a variety of lifestyles such as planktonic free-living or surface-attached biofilm modes, enabling their endurance in a range of environments including extreme settings. Metabolic changes have been recognized between these two phenotypes (Favre et al., 2018). It has been demonstrated that biofilm exudates contain compounds responsible for breaking dormancy of soil microbial, faunal and plant seed banks formed under stress, leading to regain lost biodiversity in degraded ecosystems (Seneviratne and Kulasooriya, 2013; Herath et al., 2017). Moreover, the biofilm exudates contain protein network components (e.g. RNA, proteins etc.), and also metabolic and signaling network components (e.g. polysaccharides, QS molecules etc.), which act as sub networks of the bulk network in the soil ecosystem. As a result, when 
compared to their monoculture forms, beneficial biofilms in the rhizosphere reinstate microbe-mediated networks for enhanced cycling of nutrients and their availability to crop growth while improving crop productivity and soil fertility (Seneviratne and Jayasinghearachchi, 2005).

These biofilms occur naturally in the soil with a low density, but it is not enough to have a significant effect (Bandara et al., 2006). Therefore, in vitro development and application of biofilms as biofertilizers, known as BFBFs is important for enriching agricultural productivity in ecofriendly manner.

Generally, BFBFs too, being developed biofilms increase microbial abundance in the soil-plant system, particularly endophytes (Seneviratne et al., 2017), as explained above. Microbial endophytes play a major role in crop production, by promoting plant growth and resistivity to pathogens (Feng et al., 2006). However, plants in degraded agro-ecosystems show poor endophytic diversity, leading to susceptibility to pathogens (Herath et al., 2017).Thus, BFBFs act as not only biofertilizers, but also as agents to reduce biotic stress in the environment. The BFBFs contain beneficial fungal-bacterial communities in a biofilm mode (Seneviratne et al., 2008a).Studies that have been carried out with BFBF application have shown that it facilitates biological $\mathrm{N}_{2}$ fixation in non-legumes (e.g. rice), while solubilizing phosphorus and other nutrients required for crop growth via beneficial interactions between microbes and the soil (Seneviratne et al., 2008a).

Rice (Oryza sativa L.), the most widely consumed staple food for a large part of the world's human population, is the agricultural commodity with the third-highest worldwide production. In Sri Lanka, the largest agricultural land area (34\% or 0.88 million ha) is occupied by rice, being the staple food. It is cultivated as a wetland crop. About 1.8 million farm families are engaged in paddy cultivation island-wide producing 4,819 Mt rice annually (Census and Statistics, 2016). Paddy is mainly cultivated solely using chemical inputs as nutrients and agrochemicals.

Amarathunga et al. (2018) and Wickramasinghe et al. (2018) showed that the CF alone application could not support an improved plant growth and yield in rice, which could be achieved by combining CF with BFBF. A similar result was observed in the later studies (2019/2020) conducted by the Department of Agriculture, Sri Lanka. This is because the application of BFBF improves the soil-plant-microbial interactions and leads to enhanced nutrient use efficiency and increased yield while cutting down the CFs (Seneviratne et al., 2008a; Premarathna et al., 2018). Therefore, the present study was designed to reveal the effect of BFBF on re-establishing networks in the soil ecosystem in comparison to that of farmers' $\mathrm{CF}$ alone application, using rice as the test crop.

\section{MATERIALS AND METHODS}

\section{Field sites and the experiment}

The field experiments were carried out during 2018-2019 period in four major paddy growing districts of Sri Lanka;
Ampara $\left(07^{\circ} 05^{\prime} \mathrm{N} 81^{\circ} 45^{\prime} \mathrm{E}\right.$, average annual temperature $27^{\circ} \mathrm{C}$, elevation above sea level $37 \mathrm{~m}$, average annual rainfall $1,858 \mathrm{~mm})$, Kurunegala $\left(07^{\circ} 45^{\prime} \mathrm{N} 80^{\circ} 15^{\prime} \mathrm{E}\right.$, average annual temperature $26^{\circ} \mathrm{C}$, elevation above sea level $116 \mathrm{~m}$, average annual rainfall $2000 \mathrm{~mm}$ ), Hambanthota $\left(06^{\circ} 15^{\prime} \mathrm{N} 81^{\circ} 10^{\prime} \mathrm{E}\right.$, average annual temperature $28^{\circ} \mathrm{C}$, elevation above sea level $1 \mathrm{~m}$, average annual rainfall 1,045 $\mathrm{mm})$ and Polonnaruwa $\left(07^{\circ} 56^{\prime} \mathrm{N} 81^{\circ} 0^{\prime} \mathrm{E}\right.$, average annual temperature $27^{\circ} \mathrm{C}$ elevation above sea level $60 \mathrm{~m}$, average annual rainfall 1,678 $\mathrm{mm}$ ) districts consisting with variable soil types, particularly red yellow podzolic with laterite, low humic gley, non-calcic brown, reddish brown earth, solodize solonets and regosol (Ministry of Agriculture, 2014).

In all, 74 representative paddy fields (each $c a$. 0.4 ha of land area) in 37 locations spreading over thousands of hectares in Ampara $(n=6)$, Kurunegala ( $n$ $=28)$, Hambanthota $(n=16)$ and Polonnaruwa $(n=24)$ districts with diverse soil types were selected to conduct the field experiments. Two consecutive, uniformly managed paddy fields were used to apply two treatments separately. Previously, Amarathunga et al. (2018) and Wickramasinghe et al. (2018) tested a range of treatments consisting of different levels of $\mathrm{CF}$ alone and $\mathrm{CF}+\mathrm{BFBF}$ combinations $[(0,65 \%, 80 \%$ and $100 \%$ of $\mathrm{CF}$ recommended by the Department of Agriculture (DOA), and BFBF $+65 \% \mathrm{CF}$ and $\mathrm{BFBF}+80 \% \mathrm{CF})]$. A similar study was conducted later (2019/2020) by the DOA, Sri Lanka. They showed that the optimum level of CF that should be coupled with BFBF was $225 \mathrm{~kg} / \mathrm{ha}$. When it was coupled with BFBF, it gave a better yield than $225 \mathrm{~kg} \mathrm{CF} /$ ha alone application. Thus, this was used as the recommended practice of BFBF. The treatments of the present study were (a) BFBF practice $\mathrm{BFBF}$ is a fungal-bacterial biofilm (Seneviratne et al., 2008b), which is now a patented [Sri Lanka patent no. 15958 (2013)] commercial product, and hence exact composition cannot be revealed due to Intellectual Property Right reasons $\}$, [2.5 L of BFBF with $225 \mathrm{~kg} \mathrm{CF} /$ ha (Urea 150, TSP 40 and MOP $35 \mathrm{~kg} / \mathrm{ha}$ )], and (b) Farmers' practice [425 kg CF/ha (Urea 284, TSP 76 and MOP $66 \mathrm{~kg} / \mathrm{ha}$ )]. To be realistic, farmers' CF rate was used, because in an initial survey, it was found that $>90 \%$ of the farmers do not use the CF recommendation of the DOA. Paddy was broadcasted and irrigation water was managed separately in the two fields, without mixing from surrounding fields. The BFBF was applied to the paddy fields of 0.4 ha by mixing $500 \mathrm{~mL}$ of BFBF with $4 \mathrm{~L}$ of fine sand at 2 weeks and 6 weeks after broadcasting. Our past studies showed that fine sand with CF does not show significant difference in plant growth from the CF alone application (data not shown). Therefore, in applying $\mathrm{CF}$, it was not mixed with the sand. The two consecutive treatment plots were taken as a block design in each site. Thirty-seven field locations acted as replicates.

\section{Sample collection}

Two random rice hills with rhizosphere soil were uprooted carefully by digging around the root zone without damaging the root system at $50 \%$ flowering stage from each paddy field. Due to contrasting difference of plant growth between the two treatments, we limited to two plants in uprooting, 
which minimized the damage to the plants growing in the paddy fields. Total sample number for each practice across the four districts was 74, which also justified the adequacy of sample number per practice. Seed samples were also collected from two random hills at physiological maturity stage.

\section{Plant analysis}

Soil was removed carefully from roots. Then, the plants were washed carefully without damaging the root system. Roots and shoots were separated and oven dried at $65{ }^{\circ} \mathrm{C}$ for constant weight, and then root dry weight (RDW) and shoot dry weight (SDW) were recorded using a top loading balance. Yield was analyzed by performing five $1 \mathrm{~m} \times 1 \mathrm{~m}$ crop cuts in each field. Thousand grain weight (TGW) was measured using top loading balance.

\section{Soil analysis}

It is critical to ensure that the data needed to assess soil quality and health is generated by reproducible methods selected through a transparent process (Wander et al., 2019). In this study, soil $\mathrm{pH}$, soil moisture (SM), soil total nitrogen (STN), soil total phosphorus (STP), soil potassium (SP), soil organic carbon (SOC) and soil labile carbon (SLC) were selected as the parameters fulfilling that criterion.

In fresh soil samples, SM was determined by oven drying fresh soil at $105{ }^{\circ} \mathrm{C}$ until a constant weight. Soil pH was determined using soil:water 1:2.5 ratio. Rest of the soil samples was air-dried for analyzing other parameters mentioned above. The dried soil was grinded using mortar and pestle, and passed through $0.5 \mathrm{~mm}$ sieve. SOC was determined using Walkley-Black colorimetric method (Baker, 1976), whereas STN and STP were measured using distillation and titration method (Bremner and Mulvaney, 1982) and colorimetric method (Anderson and Ingram, 1993), respectively. SP was analyzed using modified Morgan extract (McIntosh, 1969) and SLC was analyzed using permanganate oxidizable carbon method (Weil et al., 2003).

\section{Microbial analysis}

Endophytic diazotrophs (ED) and non diazotrophs (END) in plant leaves were enumerated by culturing them at $10^{-6}$ dilution in combined carbon medium (CCM) (Rennie, 1981) and modified CCM medium $\left(\mathrm{CCM}+\mathrm{NH}_{4} \mathrm{NO}_{3}\right)$, respectively. The surfaces of leaves were sterilized using $70 \%$ ethanol before extracting the endophytes. Colony counts were taken after 48 hours.

\section{Data analysis}

Means and correlations of all the variables of BFBF practice and farmers' CF practice were calculated. T-test was performed for mean comparison after confirmation of normal distribution of data using normality test. All data were analyzed statistically using Minitab 17 version. Network analysis was performed by Gephi software based on the correlation analysis of the parameters. Gephi has been used widely in visualizing soil-plant-microbial networks also in paddy cultivation (Bakker et al., 2014; Ji et al., 2018; Sun et al., 2018). Probability level considered for statistical significance of the results was 0.10 , because in agricultural field research, there is an allowance to consider the significance even up to $10 \%$ probability level (Mullen et al., 2008).

\section{RESULTS AND DISCUSSION}

\section{Soil, plant and microbial parameters}

Significant increases of TGW and END were observed in the BFBF practice over the farmers' CF practice (Table 1; $p=0.063$ and $p=0.082$, respectively). Furthermore, RDW, SDW and yield were significantly higher in the BFBF practice than those of the farmers' CF practice (Table 1; $p=0.017, p=0.000$ and $p=0.002$, respectively). The yield increase of the BFBF practice was ca. $24 \%$. However, soil pH, SM, STN, STP, SP, SOC, SLC and ED were not significantly different between the two practices (Table 1; $p>0.10)$.

The yield increase of the BFBF practice over farmers' CF alone practice is possibly due to improved grain filling as reflected from increased TGW (Table 1). Enhanced plant growth with the BFBF application has contributed to this, as shown by significantly increased SDW and RDW.

\section{Networks of BFBF and farmers' CF practices}

Fifteen relationships (12 positively and 3 negatively correlated) were observed in the network of the farmers' CF practice whereas 20 relationships (13 positively and 7 negatively correlated) were observed in the BFBF practice. In the farmers' $\mathrm{CF}$ practice, the grain yield was directly related only to the STN $(r=0.440, p=0.077$, Figures 1 and $3)$. However, in the BFBF practice, five parameters viz. soil $\mathrm{pH}, \mathrm{SOC}, \mathrm{STN}, \mathrm{STP}$ and SP were directly related to the grain yield $(r=0.318, p=0.099 ; r=0.290, p=0.107 ; r=0.470$, $p=0.049 ; r=0.584, p=0.002$ and $r=-0.457, p=0.033$, respectively). Moreover, relationships between ED and STP were observed in the networks of both farmers' CF and BFBF practices $(r=-0.423, p=0.044$ and $r=-0.578$, $p=0.004$, respectively). However, separate relationships between ED and SLC, and ED and SM were noted in the BFBF and farmers' CF practices, respectively ( $r=0.830$, $p=0.003$ and $r=0.462, p=0.046$, respectively).

In the farmers' $\mathrm{CF}$ practice, the grain yield was significantly limited by the STN $(p<0.10$, Figure 1 and 3 ). However, in the BFBF practice, a number of soil, plant and microbial parameters controlled the yield (Figure 2 and 4). Here, plant ED association promoted the plant growth, possibly by direct and indirect mechanisms such as fixing $\mathrm{N}_{2}$, producing plant growth hormones, improving nutrient uptake, suppressing pathogens, solubilizing phosphate and increasing plant tolerance against biotic and abiotic stresses (Mohanta et al., 2010; Carvalho et al., 2014). In the present study, the ED of the farmers' CF practice controlled the plant growth in the vegetative phase by influencing to SDW, which was not observed in the BFBF practice, even though there was a significantly higher SDW compared to the farmers' CF practice. This could be attributed to 
important role played by the ED in supplying biologically fixed $\mathrm{N}_{2}$ to shoot growth in the farmers' CF practice due to soil $\mathrm{N}$ limitation. It has also been reported that low soil $\mathrm{N}$ promotes diazotrophic $\mathrm{N}_{2}$ fixation (Ai'shah et al.,
2009). Applied $\mathrm{N}$ has been efficiently utilized, and has not been limiting in the BFBF practice, as reflected from the significantly higher SDW and RDW, and also as depicted from the absence of relationships between EDs and SDW or RDW (Figure 2 and 4).

Table 1: Rhizosphere soil, plant and microbial parameters of the BFBF practice and farmers' CF practice of rice cultivations. Plant and soil samples were collected at 50\% flowering whereas yield parameters were obtained at physiological maturity.

\begin{tabular}{|c|c|c|c|}
\hline Parameter & $\operatorname{BFBF}(n=74)$ & $C F(n=74)$ & Difference* \\
\hline $\mathrm{pH}$ & $6.35 \pm 0.13$ & $6.32 \pm 0.09$ & $0.03(0.882)$ \\
\hline $\mathrm{SM}(\%)$ & $43.61 \pm 2.84$ & $39.79 \pm 2.00$ & $3.82(0.406)$ \\
\hline STN $(\%)$ & $0.23 \pm 0.01$ & $0.18 \pm 0.01$ & $0.05(0.178)$ \\
\hline STP (\%) & $0.36 \pm 0.06$ & $0.41 \pm 0.07$ & $0.05(0.611)$ \\
\hline $\mathrm{SP}(\mathrm{cmol} / \mathrm{kg})$ & $0.42 \pm 0.06$ & $0.37 \pm 0.06$ & $0.05(0.677)$ \\
\hline $\operatorname{SOC}(\%)$ & $1.79 \pm 0.09$ & $1.59 \pm 0.08$ & $0.2(0.158)$ \\
\hline $\mathrm{SLC}(\mathrm{mg} / \mathrm{kg})$ & $2940 \pm 501$ & $2544 \pm 339$ & $396(0.520)$ \\
\hline $\operatorname{SDW}\left(\mathrm{g} / \mathrm{m}^{2}\right)$ & $3292.5 \pm 245$ & $2150 \pm 135$ & $1142.5(0.000)$ \\
\hline $\mathrm{RDW}\left(\mathrm{g} / \mathrm{m}^{2}\right)$ & $1130 \pm 100$ & $733 \pm 128$ & $398(0.017)$ \\
\hline TGW (g) & $20.92 \pm 0.65$ & $17.73 \pm 0.72$ & $3.19(0.063)$ \\
\hline $\mathrm{ED}(\mathrm{CFU} / \mathrm{mL})$ & $191 \pm 38$ & $106 \pm 30$ & $85(0.121)$ \\
\hline $\mathrm{END}(\mathrm{CFU} / \mathrm{mL})$ & $56 \pm 5$ & $43 \pm 5$ & $13(0.082)$ \\
\hline Grain Yield (kg/ha) & $5860 \pm 243$ & $4733 \pm 173$ & $1127(0.002)$ \\
\hline
\end{tabular}

Mean \pm SE in each column. SE of the means was calculated using the four district means of each parameter. *Values within parentheses are probability levels at which differences are significant. Soil moisture (SM), $\mathrm{pH}$, total nitrogen (STN), total phosphorus (STP), organic carbon (SOC), labile carbon (SLC), shoot dry weight (SDW), root dry weight (RDW), thousand grain weight (TGW), yield, endophytic diazotrophs (ED), endophytic non diazotrophs (END) and soil exchangeable potassium (SP) content.

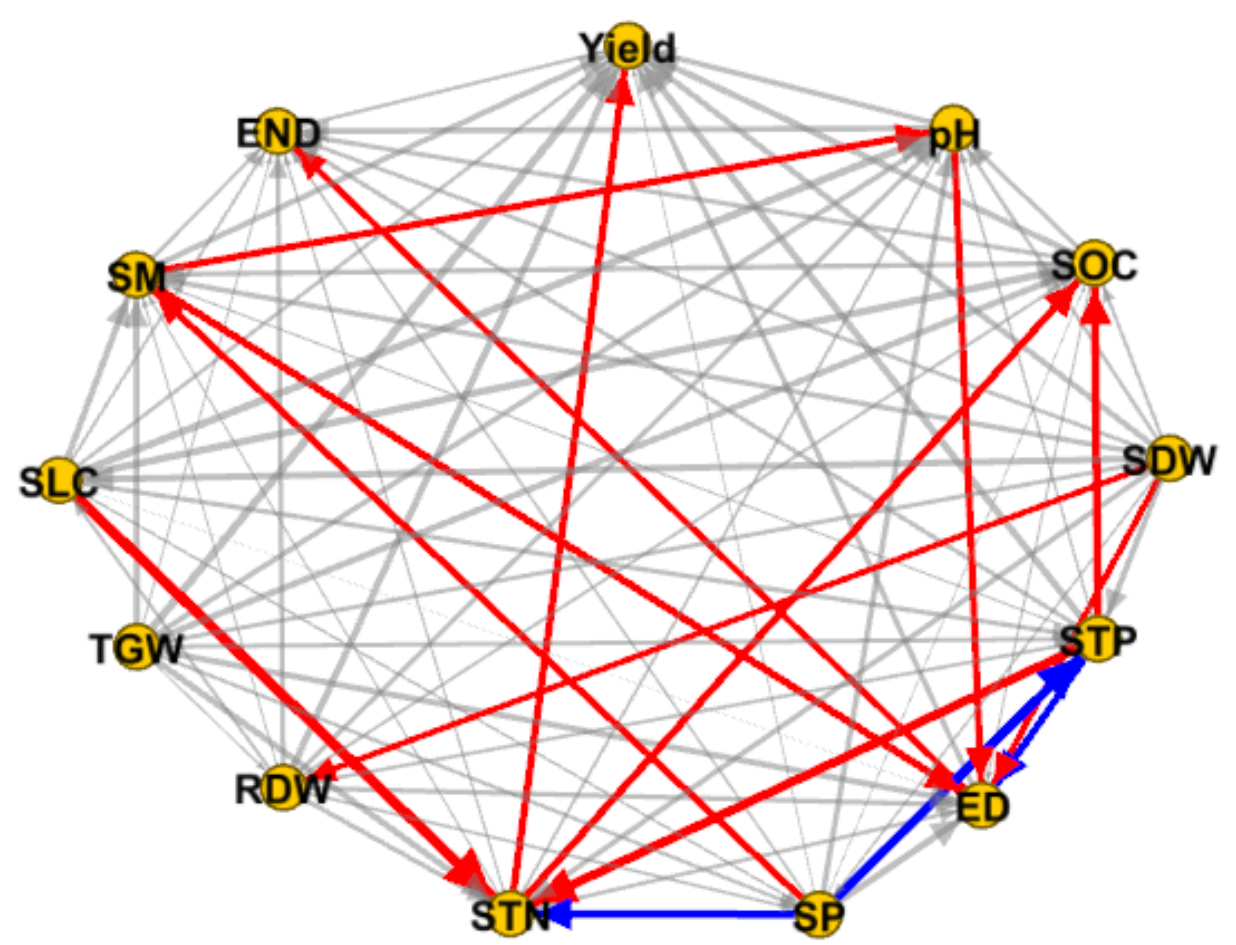

Figure 1: Network of the farmers' CF practice. Positive and negative correlations are shown in red and blue colors, respectively. The width of the arrows represents the strength of the relationships. 


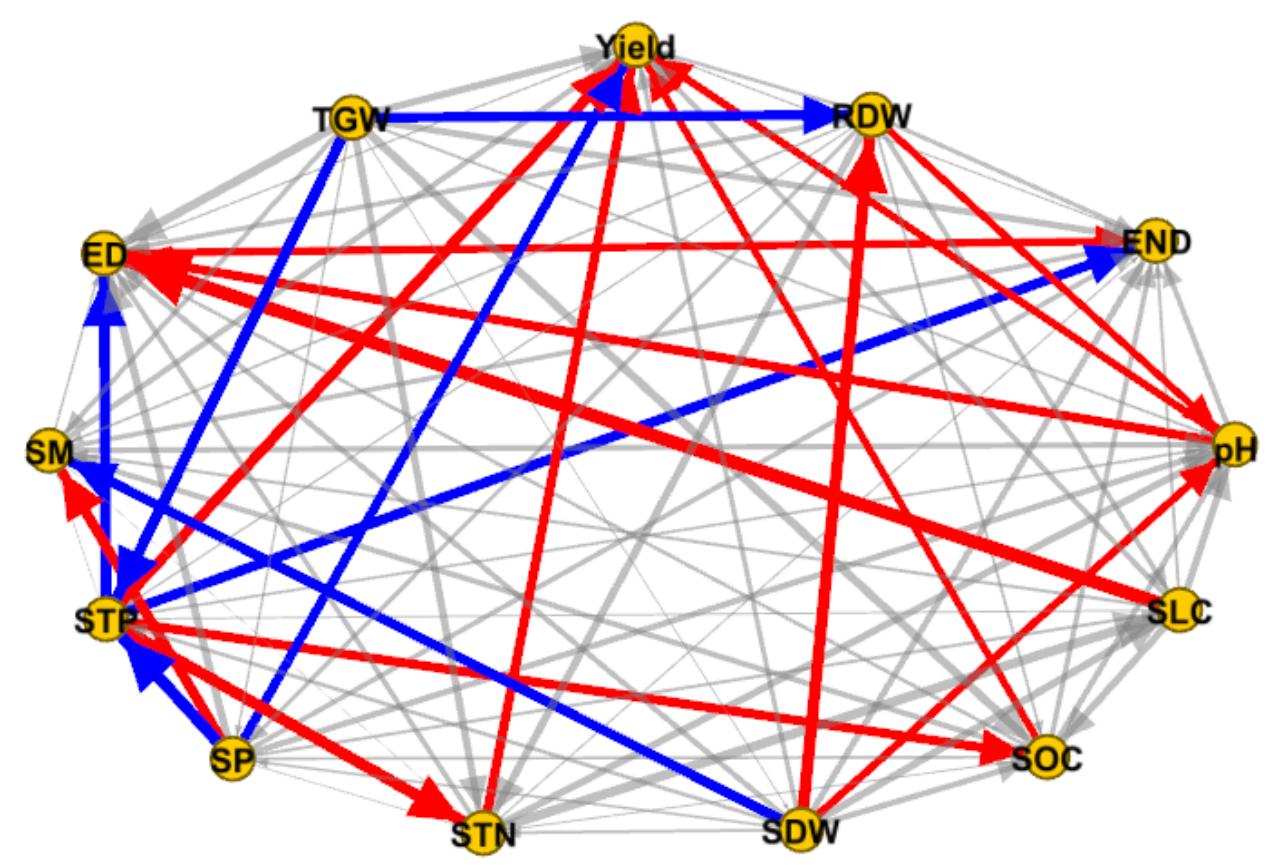

Figure 2: Network of the BFBF practice. Positive and negative correlations are shown in red and blue colors, respectively. The width of the arrows represents the strength of the relationships.

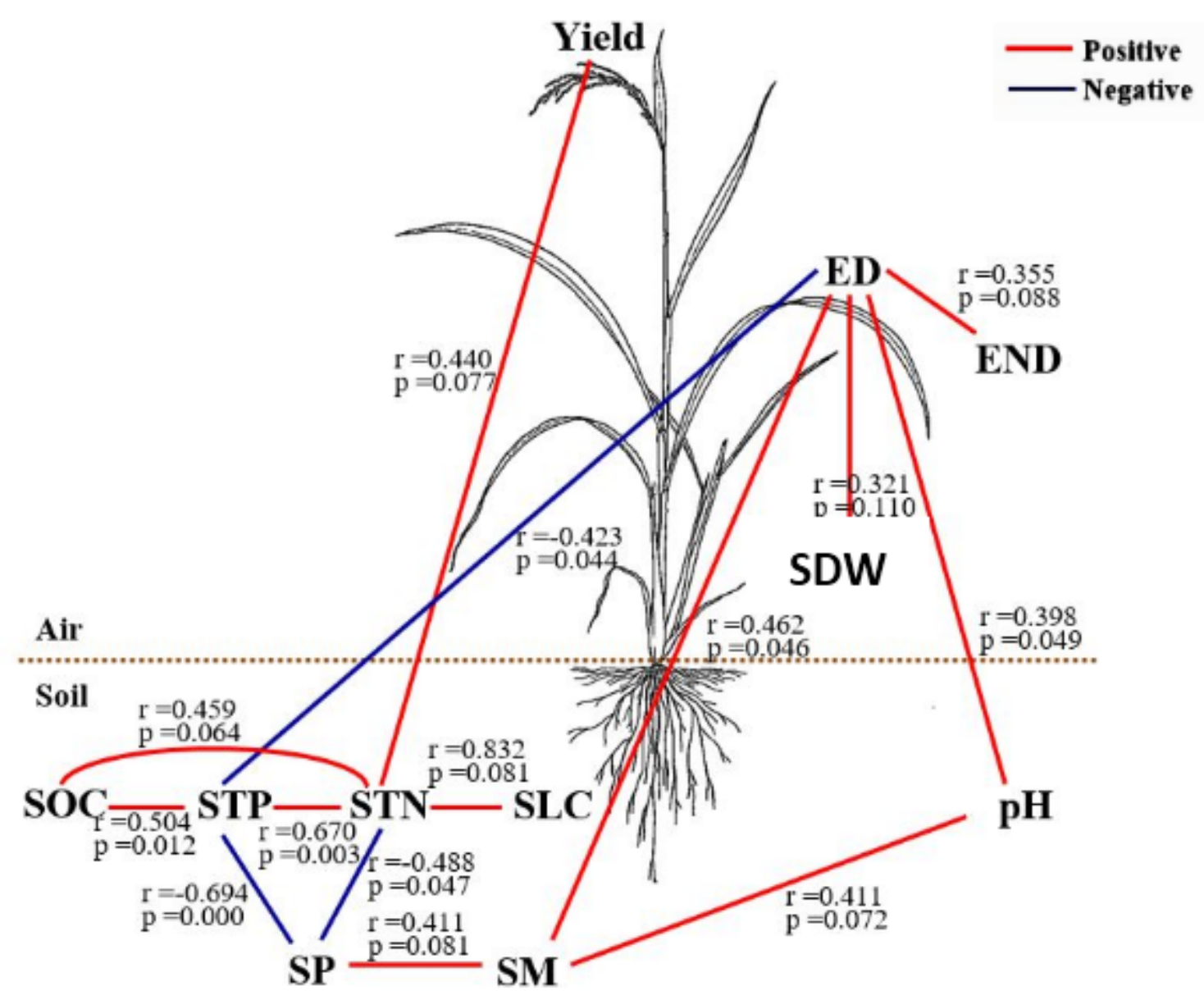

Figure 3: Opened up network of the farmers' CF practice. 


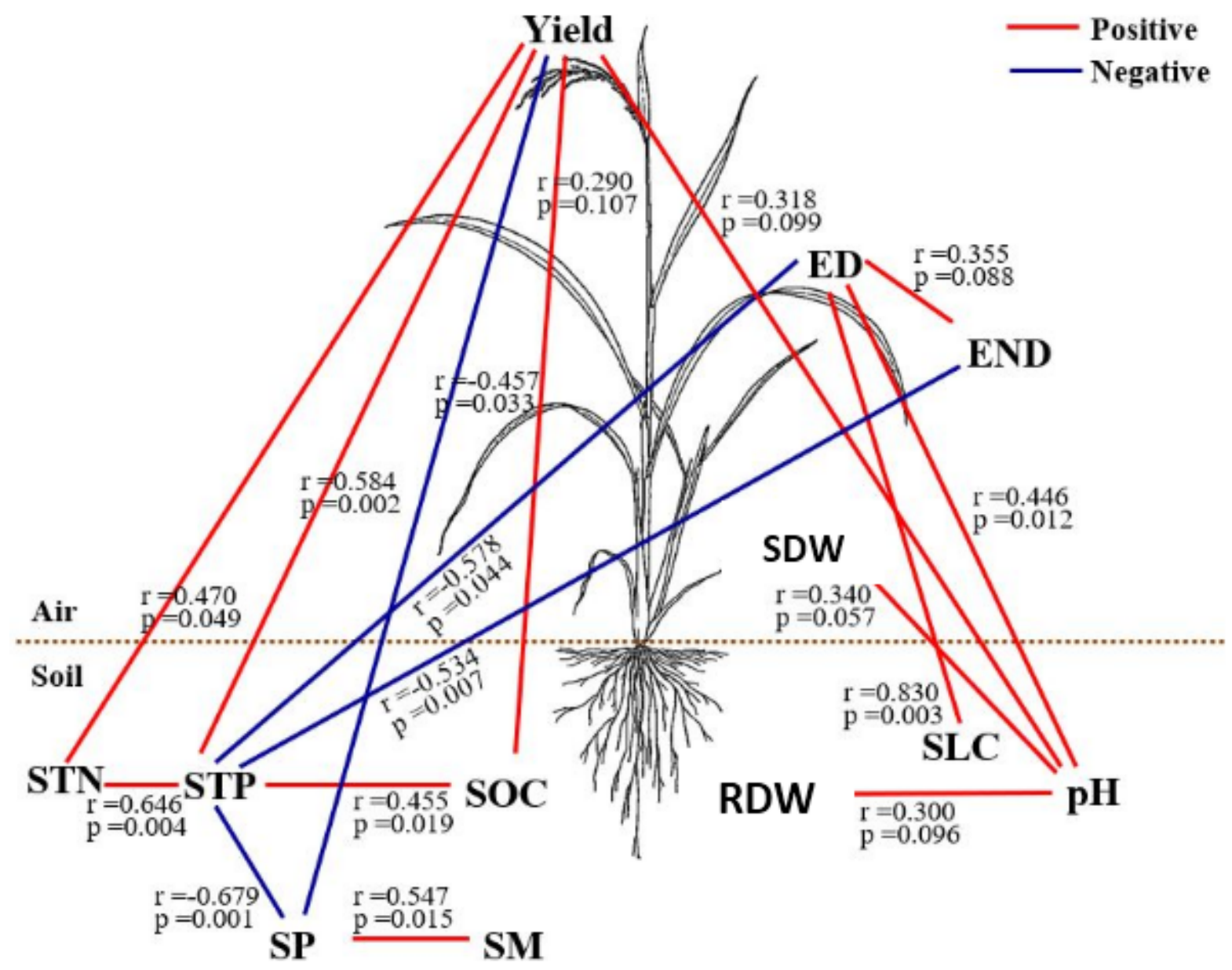

Figure 4: Opened up network of the BFBF practice.

The relationships between STP and ED in the networks of both farmers' $\mathrm{CF}$ and BFBF practices could be explained by high energy cost of diazotrophic $\mathrm{N}_{2}$ fixation (Dighe et al., 2010). As explained above in the BFBF practice, the ED have contributed to an increased plant growth as indicated from the higher SDW and RDW, which may have led to enhanced root exudation and hence increased SLC. This is depicted from the strong relationship between ED and SLC in the BFBF practice. Further, ED was related to SM in the farmers' CF practice. However, this was not observed in the BFBF practice, while SM between the two practices was not significantly different. This could be due to an indirect effect between the two parameters via SP and STP, as was observed in the both practices (Figure 3 and 4). The SP has been observed to mitigate SM stress of plants (Sangakkara et al., 2000). The SP was yield limiting only in the BFBF practice possibly due to inadequate supply of SP to support the increased yield.

Interacting sub network among STN-STP-SP-SOC$\mathrm{SM}$ is common for both practices (Figure 3 and 4). In the farmers' CF practice, the grain yield has been directly controlled by the STN of the network, however in the BFBF practice, all parameters of the STN-STP-SP-SOCSM sub network have governed the yield (Figure 3 and 4). This implies that if the STN, STP, SP, SOC and/or SM would be optimized, grain yield could be further increased, showing elasticity of the parameters in the BFBF practice. But in the farmers' CF practice, if the grain yield is to be enhanced, only STN should be further increased, which is not favorable for soil diazotrophic action, and hence the soil-plant system. This clearly shows the importance of microbial interventions over chemical inputs in improving crop production in eco-friendly manner.

\section{CONCLUSION}

Most of the conventional soil-plant-microbe interaction studies in agro-ecosystems are still analyzed assuming that the system variables interact univariate and/or multivariate manner. Their interaction networks are hardly established, which are of paramount importance for understanding the real action under field conditions with several, unpredictable variables. Here we show that if the STN, STP, SP, SOC and/or SM would be optimized, grain yield could be further increased only in the BFBF practice. However, to increase yield in the farmers' CF practice, STN should be further increased, which would not be favorable to soil diazotrophic action, and hence the soil-plant system. Future studies should be conducted in order to collect data of a large number of variables as much as possible, and they should be analyzed using methods like network interactions and more advanced concepts to understand, particularly biotic and abiotic stresses for addressing them 
more effectively. This will eventually lead to design ecofriendly agro-ecosystems for sustainable agriculture.

\section{ACKNOWLEDGEMENT}

The authors are thankful to the two reviewers for constructive criticisms, which improved the manuscript. All the members of Microbial Biotechnology Unit of the NIFS are acknowledged for their support during this study. We would also like to show our gratitude to all farmers who collaborated by providing data, insights and expertise that greatly assisted the research.

\section{DECLARATION OF CONFLICT OF INTEREST}

Authors have no conflict of interest.

\section{REFERENCES}

Amarathunga, I.M.G., Seneviratne, G. and Amarasekara, M.G.T.S. (2018). Role of developed microbial biofilms on growth and yield of rice. Proceedings of the $10^{\text {th }}$ Annual Research Symposium, Rajarata University of Sri Lanka, Pp. 9.

Anderson, J.M. and Ingram, J.S.I. (1993). Tropical soil biological and fertility: a handbook of methods. Available from: https://www.researchgate.net/ profile/ John_Ingram5/publication/232141777_Tropical_Soil Biology_and_Fertility_A_Handbook_of_Methods/ links/589b556592851c942ddad326/Tropical-SoilBiology-and-Fertility-A-Handbook-of-Methods.pdf (Accessed: 29 January 2021).

Ai'shah, O.N., Amir, H.G., Keng, C.L. and Othman, A.R. (2009). Influence of various combinations of diazotrophs and chemical $\mathrm{N}$ fertilizer on plant growth and $\mathrm{N}_{2}$ fixation capacity of oil palm seedlings (Elaeis guineensis Jacq.). Thai Journal of Agricultural Science 42(3): 39-149.

Alori, E.T. and Babalola, O.O. (2018). Microbial inoculants for improving crop quality and human health in Africa. Frontiers in Microbiology 9: 2213. DOI: 10.3389/ fmicb.2018.02213.

Aussenac, R., Bergeron, Y., Gravel, D. and Drobyshev, I. (2019). Interactions among trees: a key element in the stabilizing effect of species diversity on forest growth. Functional Ecology 33(2): 360-367.

Baker, J.M. (Eds.) (1976). Marine Ecology and Oil Pollution. Applied Science Publishers Limited, Essex England, Pp. 483-536.

Bandara, W.M.M.S., Seneviratne, G. and Kulasooriya, S.A. (2007). Interactions among endophytic bacteria and fungi: effects and potentials. Journal of Biosciences 31(5): 645-650.

Bakker, M.G., Schlatter, D.C., Otto-Hanson, L. and Kinkel, L.L. (2014). Diffuse symbioses: roles of plant-plant, plant-microbe and microbe-microbe interactions in structuring the soil microbiome. Molecular Ecology 23(6): 1571-1583.

Bremner, J.M. and Mulvaney, C.S. (1982). NitrogenTotal. In: Page, A.L., Miller, R.H. and Keeney, D.R. (Eds.), Methods of Soil Analysis. Part 2. Chemical and Microbiological Properties, American Society of
Agronomy, Soil Science Society of America, Madison, Wisconsin Pp. 595-624.

Carvalho, T.L.G., Balsemão-Pires, E., Saraiva, R.M., Ferreira P.C.G. and Hemerly, A.S. (2014). Nitrogen signalling in plant interactions with associative and endophytic diazotrophic bacteria. Journal of Experimental Botany 65(19): 5631-5642.

Census and Statistics. (2016). Paddy Statistics. Available from: http://www.statistics.gov.lk/agriculture/Paddy\% 20Statistics/PaddyStats.htm (Accessed: 29 January 2021).

Chen, J., Arafat, Y., Wu, L., Xiao, Z., Li, Q., Khan, M.A., Khan, M.U., Lin, S. and Lin, W. (2018). Shifts in soil microbial community, soil enzymes and crop yield under peanut/maize intercropping with reduced nitrogen levels. Applied Soil Ecology 124: 327-334. DOI: 10.1016/j.apsoil.2017.11.010.

Favre, L., Ortalo-Magné, A., Pichereaux, C., Gargaros, A., Burlet-Schiltz, O., Cotelle, V. and Culioli, G. (2018). Metabolome and proteome changes between biofilm and planktonic phenotypes of the marine bacterium Pseudoalteromonas lipolytica. TC8. Biofouling 34(2):132-148.

Feng, Y., Shen, D. and Song, W. (2006). Rice endophyte Pantoea agglomerans YS19 promotes host plant growth and affects allocations of host photosynthates. Applied Microbiology 100: 1-5. DOI: 10.1111/j.13652672.2006.02843.x.

Fox, J.E., Gulledge, J., Engelhaupt, E., Burow, M.E. and McLachlan, J.A. (2007). Pesticides reduce symbiotic efficiency of nitrogen-fixing rhizobia and host plants. Proceedings of the National Academy of Sciences 104(24): 10282-10287.

Dighe, N.S., Shukla, D., Kalkotwar, R.S., Laware, R.B., Bhawar, S.B. and Gaikwad, R.W. (2010). Nitrogenase enzyme: a review. Der Pharmacia Sinica 1(2):77-84.

Hadgu, K.M., Rossing, W.A.H., Kooistra, L. and Van Bruggen, A.H.C. (2009). Spatial variation in biodiversity, soil degradation and productivity in agricultural landscapes in the highland of Tigray, northern Ethiopia. Food Security 1(1): 83-97.

Herath, L., Seneviratne, G., Jayasinghe, J.W. and Senanayake, D.N. (2017). Microbial biofilms and mitigation of loss of agro-biodiversity in degraded soils. Journal of the National Science Foundation of Sri Lanka 45(4): 329-335.

Jackson, L., Bawa, K., Pascual, U. and Perrings, C. (2005). Agro-biodiversity: a new science agenda for biodiversity in support of sustainable agroecosystems. Diversitasreport No. 4, Pp. 40. Available from: http://www.diversitasinterlational.org/resources/ publications/reports1/agrobiodiversity\%20SP.pdf (Accessed: 29 January 2021).

Ji, Y., Liu, P. and Conrad, R. (2018). Response of fermenting bacterial and methanogenic archaeal communities in paddy soil to progressing rice straw degradation. Soil Biology and Biochemistry 124: 70-80. DOI: 10.1016/j. soilbio.2018.05.029.

Kumar, U., Nayak, A.K., Shahid, M., Gupta, V.V., Panneerselvam, P., Mohanty, S., Kaviraj, M., Kumar, 
A., Chatterjee, D., Lal, B. and Gautam, P. (2018). Continuous application of inorganic and organic fertilizers over 47 years in paddy soil alters the bacterial community structure and its influence on rice production. Agriculture, Ecosystems and Environment 262: 65-75. DOI:10.1016/j.agee.2018.04.016.

McIntosh, J.L. (1969). Bray and Morgan soil extractants modified for testing acid soils from different parent materials 1. Agronomy Journal 61(2): 259-265.

Ministry of Agriculture. (2014). Soil Groups of Sri Lanka. Available from: http://www.agrimin.gov.lk/web/index. php/en/downloads/maps (Accessed: 29 January 2021)

Mohanta, S., Sharma, G.D. and Deb, B. (2010). Diversity of endophytic diazotrophs in non-leguminous crops-a review. Assam University Journal of Science and Technology 6(1): 109-122.

Mullen, R., Lentz, E., Labarge, G. and Diedrick, K. (2008). Statistics and agricultural research. fact sheet, agriculture and natural resources. The Ohio State University, USA. Available from: https://agcrops.osu. edu/sites/agcrops/files/imce/fertility/Statistics_ag_ research.pdf (Accessed: 29 January 2021).

Njaimwe, A.N., Mnkeni, P.N., Muchaonyerwa, P., Chiduza, C. and Wakindiki, I.I. (2018). Sensitivity of selected chemical and biological soil quality parameters to tillage and rotational cover cropping at the Zanyokwe irrigation scheme. South Africa. South African Journal of Plant and Soil 35(5): 321-328.

Pang, G., Cai, F., Li, R., Zhao, Z., Li, R., Gu, X., Shen, Q. and Chen, W. (2017). Trichoderma-enriched organic fertilizer can mitigate microbiome degeneration of mono cropped soil to maintain better plant growth. Plant and Soil 416(1-2):181-192.

Premarathna, U.M.B., Seneviratne, G. and Balasooriya, B.L.W.K. (2018). Effect of biofilm biofertilizer on agroecosystems: a network science approach. Proceedings of $17^{\text {th }}$ Agricultural Research Symposium, Wayamba University of Sri Lanka, Pp. 96-100.

Rennie, R.J. (1981). A single medium for the isolation of acetylene-reducing (dinitrogen-fixing) bacteria from soils. Canadian Journal of Microbiology 27(1): 8-14.

Sangakkara, U.R., Frehner, M. and Nösberger, J. (2000). Effect of soil moisture and potassium fertilizer on shoot water potential, photosynthesis and partitioning of carbon in mungbean and cowpea. Journal of Agronomy and Crop Science 185(3): 201-207.

Seneviratne, G. (2015). Signal transduction in edaphic ecosystems governs sustainability. Agriculture, Ecosystems and Environment 210: 47-49. DOI: 10.1016/j.agee.2015.05.006.

Seneviratne, G. and Jayasinghearachchi, H.S. (2005). A rhizobial biofilm with nitrogenase activity alters nutrient availability in a soil. Soil Biology and Biochemistry 37(10): 1975-1978.

Seneviratne, G. and Kulasooriya, S.A. (2013). Reinstating soil microbial diversity in agro-ecosystems: the need of the hour for sustainability and health. Agriculture, Ecosystems and Environment 164:181-182. DOI: 10.1016/j.agee.2012.10.002.

Seneviratne, G., Kecskés, M.L. and Kennedy, I.R. (2008a). Biofilmed biofertilisers: novel inoculants for efficient nutrient use in plants. Kennedy, I.R., Choudhury, A.T.M.A, Kecskés, M.L. and Rose, M.T. (eds.) Efficient nutrient use in rice production in Vietnam achieved using inoculant biofertilisers. Proceedings of a project (SMCN/2002/073) workshop held in Hanoi, Vietnam, 12-13 October 2007. ACIAR Proceedings No. 130, Canberra, $137 \mathrm{pp}$.

Seneviratne, G., Zavahir, J.S., Bandara, W.M.M.S. and Weerasekara, M.L.M.A.W. (2008b). Fungal-bacterial biofilms: their development for novel biotechnological applications. World Journal of Microbiology and Biotechnology 24(6): 739-743.

Seneviratne, G., Wijepala, P.C. and Chandrasiri, K.P.N.K. (2017). Developed biofilm-based microbial ameliorators for remediating degraded agro-ecosystems and the environment. In: Ahmad, I. and Husain, F.M. (Eds.), Biofilms in Plant and Soil Health, John Wiley and Sons Ltd., Chichester, United Kingdom Pp. 327335.

Sun, W., Xiao, E., Pu, Z., Krumins, V., Dong, Y., Li, B. and Hu, M. (2018). Paddy soil microbial communities driven by environment-and microbe-microbe interactions: a case study of elevation-resolved microbial communities in a rice terrace. Science of the Total Environment 612: 884-893. DOI: 10.1016/j.scitotenv.2017.08.275.

Tilman, D., Cassma, K.G., Matson, P.A., Naylor, R. and Polasky, S. (2002). Agricultural sustainability and intensive production practices. Nature 418(6898): 671677. DOI: $10.1038 /$ nature01014.

Van der Heijden, M.G.A., Bakker, R., Verwaal, J., Scheublin, T.R., Rutten, M., van Logtestijn, R. and Staehelin, C. (2006). Symbiotic bacteria as a determinant of plant community structure and plant productivity in dune grassland. FEMS Microbiology Ecology 56(2): 178187.

Wander, M.M., Cihacek, L., Coyne, M., Drijber, R., Grossman, J., Gutknecht, J.L., Horwath, W., Jagadamma, S., Olk, D., Snapp, S. and Tiemann, L. (2019). Developments in agricultural soil quality and health: reflections by the research committee on soil organic matter management. Frontiers in Environmental Science 7: 109. DOI: 10.3389/fenvs.2019.00109.

Weil, R.R., Islam, K.R., Stine, M.A., Gruver, J.B. and Samson-Liebig, S.E. (2003). Estimating active carbon for soil quality assessment: a simplified method for laboratory and field use. American Journal of Alternative Agriculture 18(1): 3-17.

Wickramasinghe, W.M.D.M., Seneviratne, G. and Benaragama, D.I.D.S. (2018). Role of biofilm biofertilizer on growth, yield and nutrition of rice. Proceedings of the $10^{\text {th }}$ Annual Research Symposium, Rajarata University of Sri Lanka, Pp. 83.

Wittebolle, L., Marzorati, M., Clement, L., Balloi, A., Daffonchio, D., Heylen, K., De Vos, P., Verstraete, W. and Boon, N. (2009). Initial community evenness favours functionality under selective stress. Nature 458(7238): 623-626. DOI: $10.1038 /$ nature07840.

Zak, D.R., Holmes, W.E., White, D.C., Peacock, A.D. and Tilman, D. (2003). Plant diversity, soil microbial communities, and ecosystem function: are there any link? Ecology 84(8): 2042-2050. 